\title{
Controlled human exposures to wood smoke: a synthesis of the evidence
}

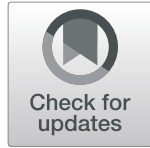

\author{
Carley Schwartz ${ }^{1 \dagger}$, Anette Kocbach Bølling ${ }^{2+}$ and Christopher Carlsten ${ }^{1 *}$ (D)
}

\begin{abstract}
Background: Exposure to particulate matter (PM) from wood combustion represents a global health risk, encompassing diverse exposure sources; indoor exposures due to cooking in developing countries, ambient PM exposures from residential wood combustion in developed countries, and the predicted increasing number of wildfires due to global warming. Although physicochemical properties of the PM, as well as the exposure levels vary considerably between these sources, controlled human exposure studies may provide valuable insight to the harmful effects of wood smoke (WS) exposures in general. However, no previous review has focused specifically on controlled human exposure studies to WS.

Results: The 22 publications identified, resulting from 12 controlled human studies, applied a range of combustion conditions, exposure levels and durations, and exercise components in their WS exposure. A range of airway, cardiovascular and systemic endpoints were assessed, including lung function and heart rate measures, inflammation and oxidative stress. However, the possibility for drawing general conclusions was precluded by the large variation in study design, resulting in differences in physicochemical properties of WS, effective dose, as well as included endpoints and time-points for analysis. Overall, there was most consistency in reported effects for airways, while oxidative stress, systemic inflammation and cardiovascular physiology did not show any clear patterns.

Conclusion: Based on the reviewed controlled human exposure studies, conclusions regarding effects of acute WS exposure on human health are premature. Thus, more carefully conducted human studies are needed. Future studies should pay particular attention to the applied WS exposure, to assure that both exposure levels and PM properties reflect the research question.
\end{abstract}

Keywords: Review, Wood smoke, Controlled human exposure, Airway, Systemic, Inflammation

\section{Background}

Exposure to wood smoke (WS) is a global health risk. Despite the development of cleaner technologies for cooking and heating, too many people remain exposed to pollution from combustion of biomass, including wood. There are approximately 3 billion people who

\footnotetext{
* Correspondence: carlsten@mail.ubc.ca

${ }^{+}$Carley Schwartz and Anette Kocbach Bølling contributed equally to this work.

${ }^{1}$ Department of Medicine, Division of Respiratory Medicine, University of British Columbia, P: 604-875-4729, 2775 Laurel Street 10th Floor, Vancouver, BC V5Z 1M9, Canada

Full list of author information is available at the end of the article
}

currently use cooking methods that produce indoor air pollution, whether through open fires or stoves, often fuelled by wood [1]. Indoor air pollution, including that due to wood combustion, presents a severe health risk to those exposed, causing nearly 4 million deaths globally each year [1]. Even in developed countries, wood stove usage for heating has increased, with approximately 1.9 million households in the US using wood as the main fuel for home heating in 2005, with an increase to up 2.5 million households in 2014 [2]. There is also a considerable contribution from residential wood combustion to outdoor air pollution, particularly in 
developed countries, that contributes significantly to human health risks [3].

Besides residential wood burning, sources of ambient biomass-derived exposure include wildfires and agricultural burning. In 2019, wildland fire accounted for approximately $29 \%$ of emissions of particulate matter of less than or equal to $2.5 \mu \mathrm{m}$ in aerodynamic diameter $\left(\mathrm{PM}_{2.5}\right)$ in the United States [4]. This contribution to air pollution is predicted to increase, as the frequency and intensity of wildfires are estimated to increase due to climate change [5]. It has been established through many studies that wildfire smoke exposure is linked to a host of adverse health effects [6].

Long-term inhalation of WS, in concentrations relevant for ambient exposure, induces mild inflammatory effects in the airways, systemic inflammation and decreased lung function in mice and rats [3]. Accordingly, epidemiological studies have associated WS exposure with increased mortality and morbidity, most notably linked to respiratory and cardiovascular conditions. In particular, associations between WS exposure and respiratory morbidity in terms of COPD and asthma, are strong. There are various proposed mechanisms to explain these effects (through cardiovascular, inflammatory and oxidative stress pathways) however these have yet to be confirmed $[3,6]$.

The physicochemical properties of WS particulate matter (PM) vary considerably according to the conditions under which they are generated (eg, contained stove, open fireplace, forest fire, etc). Emissions from residential wood stoves have been extensively characterized and include three main classes: i) ash particles emitted during complete combustion conditions (high temperatures and sufficient oxygen supply), ii) soot agglomerates originating from high temperature but airstarved combustion, and iii) organic-dominated emissions resulting from combustion at lower temperatures $[3,7]$. Residential WS is likely to be dominated by one of these classes or contain significant fractions of several classes. Emissions from wildfires are not as well characterized [8] but are likely to contain a mixture of these classes, due to the mixed fuel and conditions occurring in such uncontrolled fires. A visualization of these classes of WS and their sources is included in Fig. 1.

The physicochemical properties of PM from WS define their intrinsic toxicity, but also their deposition probability and clearance rate. Whereas deposition of ash particles and organics has been reported to be low due to hygroscopic growth with calculated deposited fraction of $21-25 \%$ [9, 10], wood smoke particles from mixed wood combustion conditions appears to be higher (38\%) probably due to presence of more hydrophobic particles [11]. Since the WS PM classes also differ in solubility, soot is insoluble while ash and organics are generally water soluble, the particle class also affects the clearance rate. Thus, the physicochemical properties of wood smoke PM are detrimental for their impact on human health [3].

Accordingly, in controlled human exposure studies, the conditions applied to generate WS are crucial, as they determine the physicochemical properties of the generated PM and thereby their potential to cause human health effects. Consequently, the choice of combustion conditions will result in data with particular relevance for different human exposure scenarios, such as residential combustion in developed countries, indoor air pollution in developing countries or wildfires.

Several reviews have been published looking at the health effects of WS exposure [3, 6, 12-15]. These have focused mainly on epidemiology, animal exposure, or in vitro studies. No previous review has focused specifically on controlled human exposure studies to WS. Therefore, the purpose of this review is to describe and summarize this particular group of studies, given their unique ability to provide detailed insight within the human context, in a manner that minimizes the risk for confounding. In doing so, we will attempt to distil patterns that emerge, elucidate gaps in knowledge and provide guidance for future directions of inquiry.

\section{Methods}

A PubMed and Web of Science search was performed to identify studies concerning controlled human exposures to WS. Controlled exposure was here defined as an experimental exposure where levels of PM and combustion gas exposure is pre-determined and maintained by the researchers (environmental exposure is eliminated). The search was limited to only include experiments involving human subjects. The search terms used were ((Wildfire) OR (Woodsmoke) OR ((Wood) AND (Smoke)) AND ((Human) (AND Exposure)) OR (Exposure)). This search strategy produced 1195 publications from PubMed and 1344 from Web of Science (August 2019). The number of publications were narrowed down to 177 from PubMed and 207 from Web of Science through title review. Between these, 132 were duplicates and another 212 were removed during the review of the publication abstracts. From these 41 remaining publications those that involved environmental (non-controlled) exposure, animal studies, in vitro studies, exposures other than WS or pellets, and other review publications were eliminated. This resulted in 22 publications that involved controlled human exposure to WS, with an additional 3 publications identified during review, resulting in a total of 22 (Fig. 2).

The exposure conditions applied in the 12 human exposure studies are grouped in terms of the PM class dominating the exposure (Table 1; organic carbon (OC), 


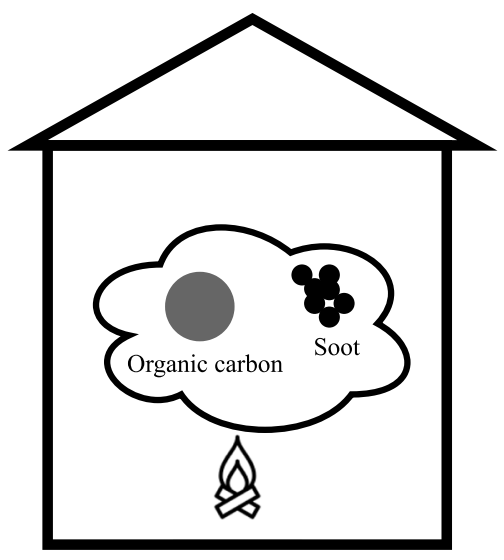

$\begin{array}{ll}\text { WS source: } & \begin{array}{l}\text { Indoor air pollution from } \\ \text { cooking and heating }\end{array} \\ \text { Fuel properties: } & \begin{array}{l}\text { Varying fuel type and moisture } \\ \text { content, often poor fuel quality }\end{array} \\ & \begin{array}{l}\text { Low temperature incomplete } \\ \text { combustion due to open fires or } \\ \text { combustion conditions: }\end{array} \\ \begin{array}{l}\text { primitive stoves, often no } \\ \text { chimney, resulting in poor } \\ \text { oxygen supply }\end{array}\end{array}$

Fig. 1 WS characteristics and sources

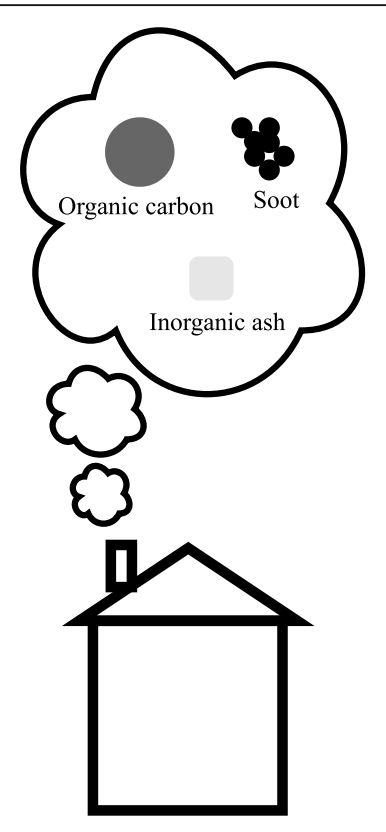

Residential wood combustion

Primarily logs with relatively low moisture content, to some extent also pellets and saw dust

Varying from medium to high temperature combustion, often in single stage stoves, resulting in medium to high oxygen supply. In addition, both smouldering combustion and complete combusion may occur

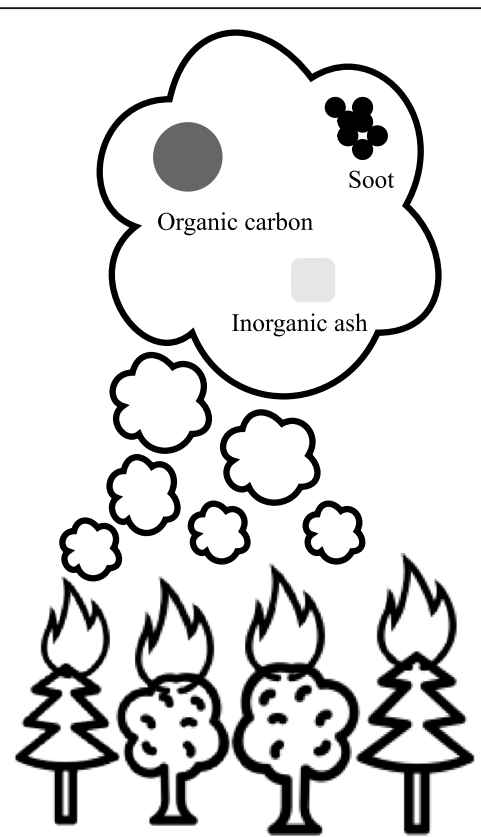

Wildfires

Large variation in materials and moisture content

Varying from smouldering to high temperature incomplete combustion with varying oxygen supply depending and wind conditions and fuel properties soot, inorganic ash, or a combination of these classes). The basis for the categorization is provided in Supplementary Material. For most American studies, the physicochemical properties of the PM applied is characterized based on provided information regarding stove type and fuel, including loading frequency, weight and humidity, in combination with available literature regarding WS PM characteristics (Supplementary material, Table S1).

\section{Results}

\section{Summary of study characteristics}

The 23 identified publications were based on 12 human controlled exposure studies. The duration of the exposure varied from 1 to $4 \mathrm{~h}$ and seven of the studies included an exercise component (Table 1). The PM mass concentrations applied varied among the studies, ranging from $\sim 100$ to $1000 \mu \mathrm{g} / \mathrm{m}^{3}$. Studies varied in size and design with the number of subject ranging from 10 to 48 participants. The majority (7) of the studies use a randomized double-blinded crossover exposure design with
3 studies non-randomized and 2 studies non-crossover. The degree of physical activity also varied between the studies, affecting the PM deposition and therefore the effective dose, as exercise can increase particle deposition by several fold [37]. Thus, in studies including an exercise component, the effective dose is likely to be considerably higher than in studies with similar PM concentration and exposure duration but without an exercise component. Since the physicochemical properties of the applied WS PM also affects the effective dose, the exposure concentrations indicated in Table 1 should be interpreted with caution.

The stove, fuel type, and combustion conditions also varied among the studies, conferring differences in the physicochemical properties of the applied WS PM. Since these properties affect both the intrinsic PM toxicity as well as PM deposition probability and clearance rate, this information is of importance in the comparison and interpretation of studies. The studies performed in the Nordic countries generally provide a thorough 




Fig. 2 Review process algorithm

characterization of the physicochemical properties of the WS, such as chemical analysis of polycyclic aromatic hydrocarbons (PAHs) and alkali metals, particle numbers, content of elemental and organic carbon (EC and OC, respectively) etc. In contrast, other studies generally limit their exposure characterization to the PM mass and number concentrations and, in some cases, associated gasses. For the purpose of this review, publications have been sorted by WS emission classes/combustion conditions from incomplete combustion to high temperature complete combustion in all tables.

For smoldering combustion (air-starved combustion in a conventional wood stove without advanced combustion technology), the emissions are dominated by organics [16-19]. Similarly, air-starved operation of a pellet stove [20] will also result in emissions dominated by organics, although soot and ash particles are also emitted. With increasing temperatures and air supply, soot aggregates will be formed, resulting in emission of a mixture of soot and organics from flaming combustion in stoves, fireplaces and open fires [21-30]. Upon even more complete combustion conditions (eg, highest temperatures in stoves with good air supply) soot is reduced to inorganic ash, consisting of elements that are refractory to combustion [31-33, 38]. Emissions from optimal operation of pellet stoves is dominated by these water-soluble ash particles. High temperature combustion in conventional wood stoves with insufficient air supply will result in emissions dominated by soot containing high PAH levels and, depending on the air supply, formation of inorganic ash may also take place [19, 34-36]. The dominating PM class for each study is listed in
Tables 1,2,3,4,5, and studies are sorted by combustion conditions and/or dominating PM class.

Four main groups of biological endpoints were assessed in the publications: airway inflammation, systemic effects, markers of oxidative stress, and changes in cardiovascular physiology (Tables 2,3,4,5). The following will summarize each of the publications resulting from studies that contributed to the collection of endpoint data with regard to WS exposures. One study only assessed subjective symptoms by a questionnaire and is not included in the following [38].

\section{Study-specific methods and outcomes}

Ghio et al [16] investigated the effect of WS generated by smouldering combustion conditions on pulmonary and systemic inflammation. Participants were exposed for $2 \mathrm{~h}$ to organics-dominated red oak WS created through an electric heating element placed inside a conventional woodstove. Deposition of the WS was also increased through 15-min intervals of exercise and rest on a stationary bike. Neutrophils in blood increased significantly immediately after exposure. In addition, the neutrophil numbers increased significantly in blood, bronchoalveolar lavage (BAL; a more distal airway sampling technique) and bronchial wash (BW; a more proximal airway sampling technique) samples $20 \mathrm{~h}$ after exposure. The pro-inflammatory cytokine interleukin 1 beta (IL-1 $\beta)$ and the toxicity marker lactate dehydrogenase (LDH) also increased significantly in blood after WS exposure. This publication also found changes in cardiovascular physiology with a significant decrease in maximal heart rate immediately following WS exposure. Although this is the first controlled human WS exposure 
Schwartz et al. Particle and Fibre Toxicology

(2020) 17:49

Page 5 of 17

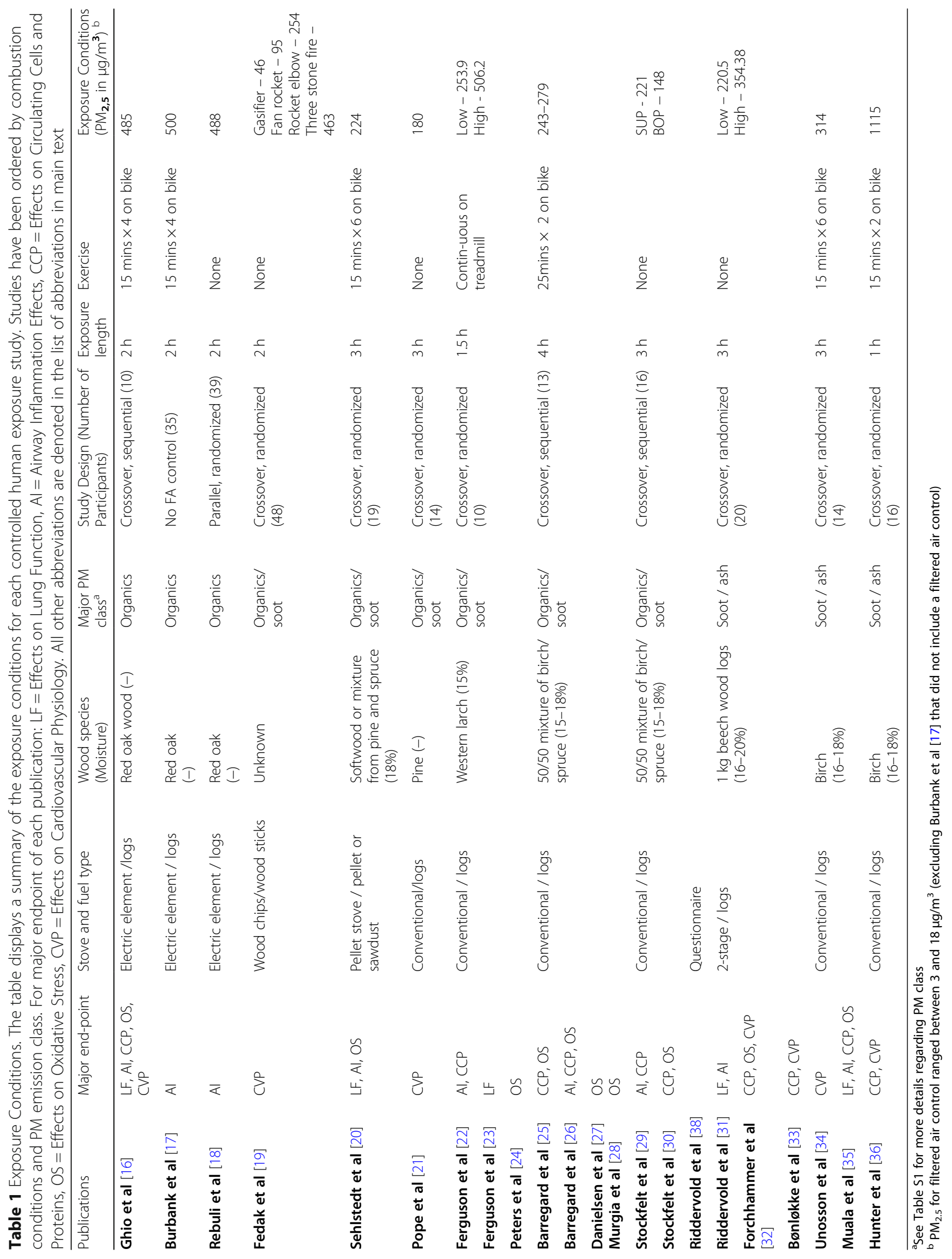




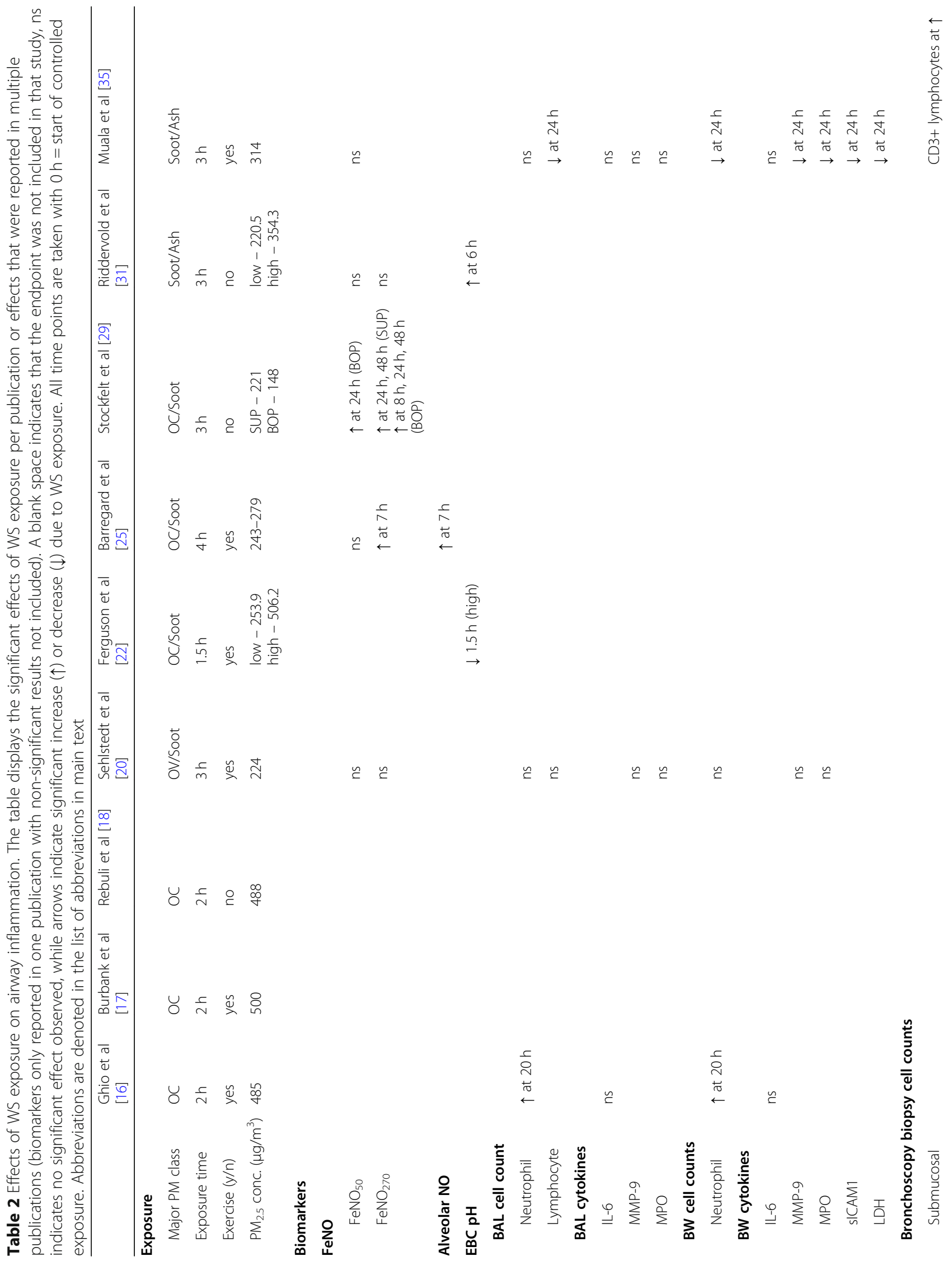




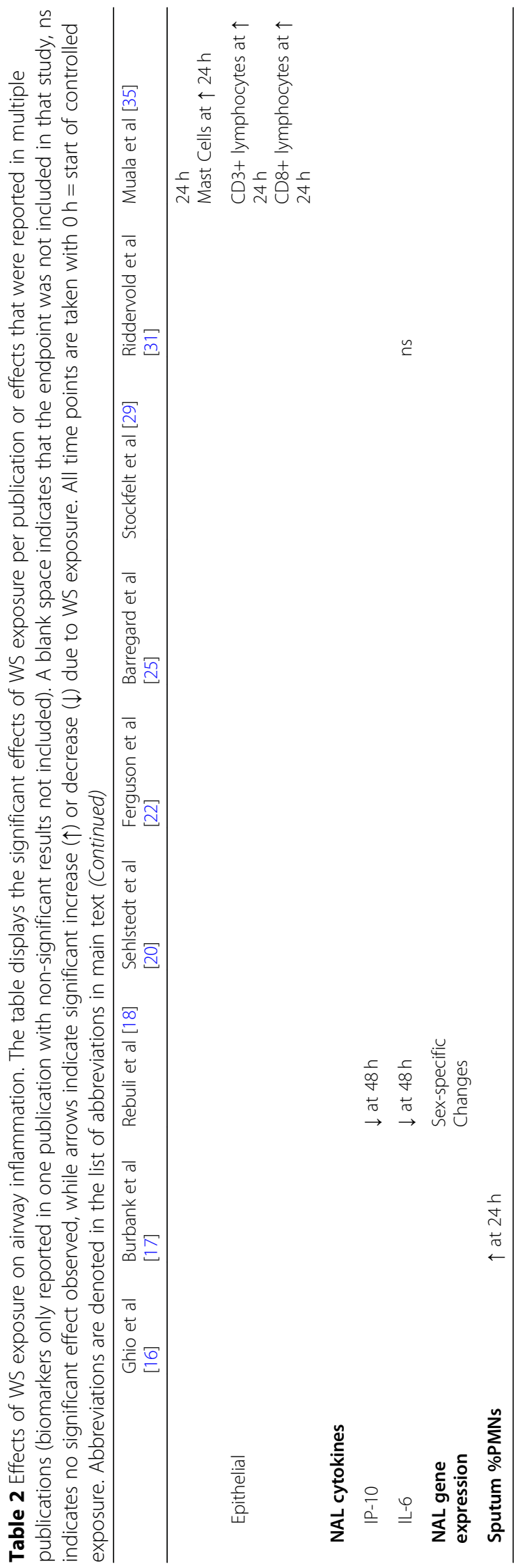




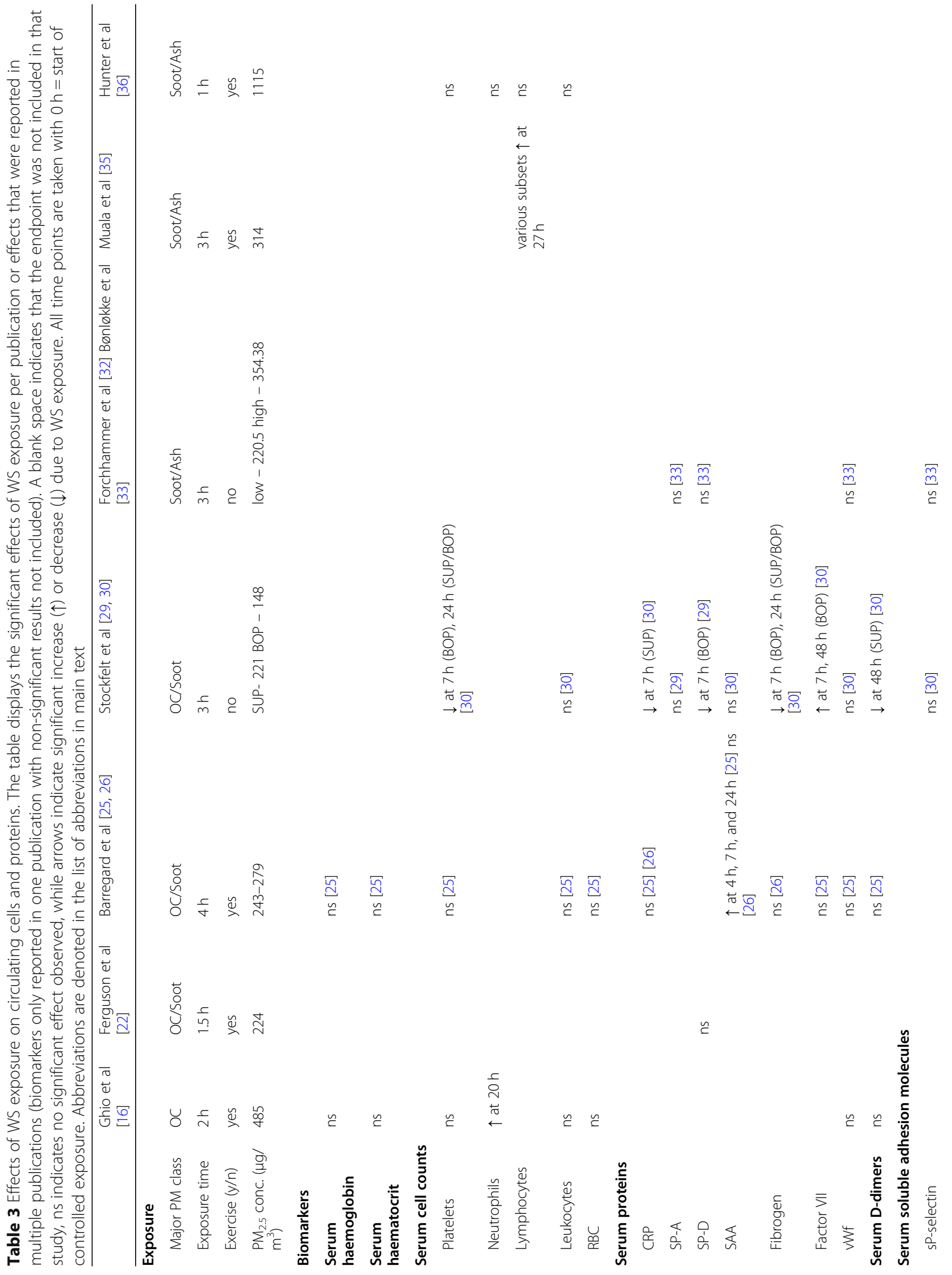




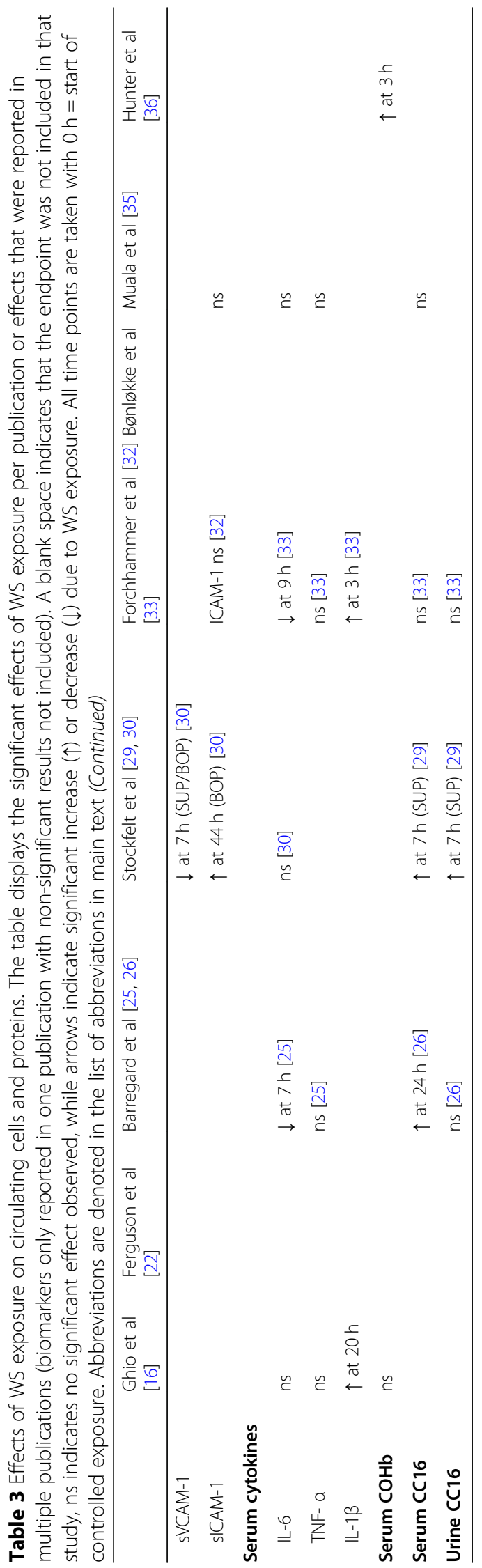


Table 4 Effects of WS exposure on markers of oxidative stress. The table displays the significant effects of WS exposure per publication or effects that were reported in multiple publications (biomarkers only reported in one publication with non-significant results not included). A blank space indicates that the endpoint was not included in that study, ns indicates no significant effect observed, while arrows indicate significant increase $(\uparrow)$ or decrease $(\downarrow)$ due to WS exposure. All time points are taken with $0 \mathrm{~h}=$ start of controlled exposure. Abbreviations are denoted in the list of abbreviations in main text

\begin{tabular}{|c|c|c|c|c|c|c|c|}
\hline & $\begin{array}{l}\text { Ghio } \\
\text { et al } \\
{[16]}\end{array}$ & $\begin{array}{l}\text { Sehlstedt } \\
\text { et al [20] }\end{array}$ & $\begin{array}{l}\text { Ferguson et al [22] } \\
\text { Peters et al [24] }\end{array}$ & $\begin{array}{l}\text { Barregard et al }[25,26] \text { Danielsen } \\
\text { et al [27] Murgia et al [28] }\end{array}$ & Stockfelt et al $[29,30]$ & $\begin{array}{l}\text { Forchhammer } \\
\text { et al [32] }\end{array}$ & $\begin{array}{l}\text { Muala } \\
\text { et al [35] }\end{array}$ \\
\hline \multicolumn{8}{|l|}{ Emissions } \\
\hline $\begin{array}{l}\text { Major PM } \\
\text { class }\end{array}$ & OC & OC/Soot & OC/Soot & OC/Soot & OC/Soot & Soot/Ash & Soot/Ash \\
\hline $\begin{array}{l}\text { Exposure } \\
\text { time }\end{array}$ & $2 \mathrm{~h}$ & $3 \mathrm{~h}$ & $1.5 \mathrm{~h}$ & $4 \mathrm{~h}$ & $3 \mathrm{~h}$ & $3 \mathrm{~h}$ & $3 \mathrm{~h}$ \\
\hline $\begin{array}{l}\text { Exercise } \\
(y / n)\end{array}$ & yes & yes & yes & yes & no & no & yes \\
\hline $\begin{array}{l}\mathrm{PM}_{2.5} \\
\text { conc. }(\mu \mathrm{g} / \\
\left.\mathrm{m}^{3}\right)\end{array}$ & 485 & 224 & $\begin{array}{l}\text { low - } 253.9 \text { high - } \\
506.2\end{array}$ & $243-279$ & SUP - 221 BOP - 148 & $\begin{array}{l}\text { low }-220.5 \\
\text { high }-352.38\end{array}$ & 314 \\
\hline \multicolumn{8}{|l|}{ Biomarkers } \\
\hline Serum UA & & & $\begin{array}{l}\downarrow \text { at } 1.5 \mathrm{~h} \\
\text { (combined) [24] }\end{array}$ & & & & \\
\hline $\begin{array}{l}\text { Serum } \\
\text { TEAC }^{a}\end{array}$ & & & $\begin{array}{l}\uparrow \text { at } 1.5 \mathrm{~h}, 2.5 \mathrm{~h} \\
\text { (combined) [24] }\end{array}$ & & & & \\
\hline \multicolumn{8}{|c|}{ Serum oxidative damage markers } \\
\hline 8-iso & & & $\begin{array}{l}\uparrow \text { at } 1.5 \mathrm{~h} \text { (high and } \\
\text { low) [24] }\end{array}$ & & & & \\
\hline $\mathrm{LOOH}$ & & & $\begin{array}{l}\downarrow \text { at } 2.5 \mathrm{~h} \\
\text { (combined) [24] }\end{array}$ & & & & \\
\hline 3-NT & & & $\begin{array}{l}\uparrow \text { at } 1.5 \mathrm{~h} \\
\text { (combined) [24] }\end{array}$ & & & & \\
\hline Serum MPO & & & $\downarrow$ at $1.5 \mathrm{~h} \mathrm{[24]}$ & & & & \\
\hline \multicolumn{8}{|c|}{ Serum modified purines } \\
\hline hOGG1 & & & & $\uparrow$ at $24 \mathrm{~h}[27]$ & & & \\
\hline oGG1 & & & & & & ns & \\
\hline $\begin{array}{l}\text { Serum FPG } \\
\text { sites }\end{array}$ & & & & ns [27] & & ns & \\
\hline $\begin{array}{l}\text { Urine 8-iso- } \\
\text { PGFa }\end{array}$ & & & $\uparrow$ at $24 \mathrm{~h} \mathrm{[22]}$ & & $\begin{array}{l}\downarrow \text { at } 24 \mathrm{~h}(\mathrm{BOP}), 44 \mathrm{~h} \\
\text { (SUP/BOP) [30] }\end{array}$ & & \\
\hline \multicolumn{8}{|c|}{ EBC oxidative damage markers } \\
\hline 8-iso & & & $\begin{array}{l}\uparrow \text { at } 2.5 \mathrm{~h} \\
\text { (combined) [22] }\end{array}$ & ns [28] & & & \\
\hline MDA & & & & $\uparrow$ at $24 \mathrm{~h} \mathrm{[26]}$ & ns [30] & & \\
\hline
\end{tabular}

BAL markers

$\begin{array}{ll}\text { MPO } & \text { ns } \\ \text { GSH } & \uparrow \text { at } 24 \mathrm{~h} \\ \text { GSX } & \\ \text { GSSG } & \text { ns }\end{array}$

BW markers

$\begin{array}{lll}\text { MPO } & \text { ns } & \downarrow \text { at } 24 \mathrm{~h} \\ \text { GSH } & \text { ns } & \text { ns } \\ \text { GSSG } & \text { ns } & \text { ns }\end{array}$


Table 5 Effects of WS Exposure on Cardiovascular Physiology The table displays the significant effects of WS exposure per publication or effects that were reported in multiple publications (biomarkers only reported in one publication with non-significant results not included). A blank space indicates that the endpoint was not included in that study, ns indicates no significant effect observed, while arrows indicate significant increase $(\uparrow)$ or decrease $(\downarrow)$ due to WS exposure. All time points are taken with $0 \mathrm{~h}=$ start of controlled exposure. Abbreviations are denoted in the list of abbreviations in main text

\begin{tabular}{|c|c|c|c|c|c|c|c|}
\hline & $\begin{array}{l}\text { Ghio et al } \\
{[16]}\end{array}$ & Fedak et al [19] & $\begin{array}{l}\text { Pope } \\
\text { et al [21] }\end{array}$ & $\begin{array}{l}\text { Forchhammer } \\
\text { et al [32] }\end{array}$ & $\begin{array}{l}\text { Bønløkke et al } \\
{[33]}\end{array}$ & Unosson et al [34] & $\begin{array}{l}\text { Hunter } \\
\text { et al [36] }\end{array}$ \\
\hline \multicolumn{8}{|l|}{ Emissions } \\
\hline Major PM class & OC & OC/Soot & OC/Soot & Soot/Ash & Soot/Ash & Soot/Ash & Soot/Ash \\
\hline Exposure time & $2 \mathrm{~h}$ & $2 \mathrm{~h}$ & $3 \mathrm{~h}$ & $3 \mathrm{~h}$ & $3 \mathrm{~h}$ & $3 \mathrm{~h}$ & $1 \mathrm{~h}$ \\
\hline Exercise $(y / n)$ & yes & no & no & no & no & yes & yes \\
\hline $\mathrm{PM}_{2.5}$ conc. $\left(\mu \mathrm{g} / \mathrm{m}^{3}\right)$ & 485 & $\begin{array}{l}\text { Gasifier - } 46 \text { Fan rocket - } \\
95 \text { Rocket elbow - } 254 \\
\text { Three stone fire - } 463\end{array}$ & 148 & $\begin{array}{l}\text { low }-220.5 \\
\text { high }-352.38\end{array}$ & $\begin{array}{l}\text { low - } 220.5 \\
\text { high - } 354.38\end{array}$ & 314 & 1115 \\
\hline \multicolumn{8}{|l|}{ Biomarkers } \\
\hline \multicolumn{8}{|l|}{ HRV } \\
\hline SDNN, RMSSD, pNN50 & ns & & & & ns & $\downarrow$ at $3 \mathrm{~h}$ & \\
\hline $\begin{array}{l}\text { Normalized High } \\
\text { Frequency }\end{array}$ & ns & & & & ns & $\uparrow$ at $3 \mathrm{~h}$ & \\
\hline High/Low Frequency & ns & & & & ns & ns & \\
\hline Heart rate & $\begin{array}{l}\text { maximal - } \\
\downarrow \text { at } 2 \mathrm{~h}\end{array}$ & & & & ns & $\downarrow$ at $3 \mathrm{~h}$ & ns \\
\hline Blood pressure & & $\begin{array}{l}\downarrow \text { systolic pressure at } 3 \mathrm{~h} \\
\text { (three stone fire) } \\
\uparrow \text { systolic pressure at } 24 \\
\text { (gasifier, fan rocket, three } \\
\text { stone fire) }\end{array}$ & & & & ns & ns \\
\hline MVF/MVRI & & & ns & ns & & & \\
\hline Arterial stiffness & & & & & & $\uparrow$ at $3 \mathrm{~h}$ & ns \\
\hline $\begin{array}{l}\text { Forearm blood flow - } \\
\text { bradykinin infusion }\end{array}$ & & & & & & & $\uparrow$ at $1 \mathrm{~h}$ \\
\hline ECG & ns & & & & ns & $\begin{array}{l}\text { Augmentation Index } \\
-\uparrow \text { at } 3 \mathrm{~h} \\
\text { Augmentation } \\
\text { Pressure }-\uparrow \text { at } 3 \mathrm{~h} \\
\text { Pulse Wave Velocity } \\
-\uparrow \text { at } 3 \mathrm{~h}\end{array}$ & ns \\
\hline
\end{tabular}

study to show an increased recruitment of neutrophils in the lungs, the concentrations applied were in the high range $\left(500 \mu \mathrm{g} / \mathrm{m}^{3}\right)$.

Similar WS exposure conditions to those described in Ghio et al [16] were also used by Burbank et al [17] and Rebuli et al [18], although the latter did not include the exercise component. Burbank et al [17] reported significantly increased percentages of neutrophils in sputum $24 \mathrm{~h}$ after WS exposure. The impact of subjects' glutathione S-transferases M1 (GSTM1) genotype was also assessed, and WS exposure induced a greater change from baseline in the GSTM1-null subjects than GSTM1sufficient participants. These results add to the evidence that WS exposure may induce an inflammatory response in the airways, and also suggest that individuals with GSTM1-null genotype may be more susceptible to these effects.
Rebuli et al [18] followed exposure to either filtered air (FA) or WS with administration of live attenuated influenza virus to determine how WS exposure would affect the immune response to the virus. Of all the cytokines measured in nasal lavage (NAL) samples, only interferon gamma-induced protein 10 (IP-10) levels were affected (decreased levels $48 \mathrm{~h}$ after WS exposure). This publication also noted sex-specific changes attributable to WS in gene expression of 13 genes in males and the downregulation of 18 genes in female participants.

Fedak et al [19] investigated effects of a variety of WS sources on blood pressure. This publication specifically investigated small stove technologies using stove-specific exposure concentrations based on expected real-life exposures. For this review, only stoves using wood as a fuel source are included, i.e. gasifier, fan rocket, rocket elbow and three stone fire, which resulted in EC or OC 
dominated exposures. Participants were exposed to WS or FA for $2 \mathrm{~h}$ with a 2-week washout period between exposures. Brachial blood pressure was taken at baseline, immediately post, $3 \mathrm{~h}$-post, and $24 \mathrm{~h}$-post exposure. The results from this study showed that there was a significant increase in systolic pressure $24 \mathrm{~h}$ following all WS exposures (excluding the rocket elbow stove condition). Despite application of different WS PM concentrations, no dose response was noted in the results.

Sehlstedt et al [20] utilized a pellet stove with a pine and spruce mixture to create organics-dominated WS (with soot and inorganic ash). Participants were exposed for $3 \mathrm{~h}$ with $15 \mathrm{~min}$ intervals of rest and exercise on a stationary bike. This publication investigated the effects of WS exposure on airway inflammation and lung function. The glutathione (GSH) levels were significantly increased in BAL $24 \mathrm{~h}$ after exposure, while no other markers of inflammation or antioxidant defence were significantly affected in the airways due to the WS exposure.

Pope et al [21] used an exposure setup that enabled investigation of UV-aged WS on vascular function. WS was generated in a conventional stove which was then treated with a catalyst to convert $\mathrm{CO}$ to $\mathrm{CO}_{2}$ followed by UV light treatment to artificially age the WS to more closely resemble atmospheric conditions. The exposures were dominated by OC or soot (Supplementary material, Table 1). Participants were exposed to WS for $3 \mathrm{~h}$ followed by $3 \mathrm{~h}$ exposure to FA. After a week wash-out period this protocol was repeated with the exposure conditions reversed. The microvascular responsiveness index (MVRI) was measured for each participant at baseline and immediately after each 3 -h exposure. The results from this study showed no significant changes in MVRI due to WS exposure.

Effects of WS exposure on both airway and systemic inflammatory markers were assessed by Ferguson et al [22]. Here a conventional woodstove burned Western larch for $1.5 \mathrm{~h}$ to generate soot/organics-dominated WS while participants continually exercised on a treadmill. From this, pentraxin-3 in the blood was significantly increased immediately and 1 -h post WS exposure. In exhaled breath condensate (EBC) samples, 8-isoprostane (8-iso) increased $1 \mathrm{~h}$ post-exposure and the $\mathrm{pH}$ of the sample decreased immediately post-exposure. There were also some observed changes in myeloperoxidase (MPO) and pentraxin-3 in EBC but these results did not reach significance. The authors concluded that these results suggest that there were some trends to show that this type of exposure leads to airway and systemic inflammatory effects.

Ferguson et al [23] reported effects on lung function from the same human controlled exposure study. Although a slight decrease in forced expiratory volume in
$1 \mathrm{~s}\left(\mathrm{FEV}_{1}\right)$, forced vital capacity (FVC), and the ratio of these values $\left(\mathrm{FEV}_{1} / \mathrm{FVC}\right)$ was observed, none of these results reached significance. With regard to oxidative stress markers in the same study, Peters et al [24] reported that uric acid (UA) values decrease immediately post-exposure and plasma Trolox equivalent antioxidant capacity (TEAC) levels were increased both immediately after and $1 \mathrm{~h}$ after the exposure. A biomarker for plasma oxidative stress, lipid hydroperoxides (LOOHs), was decreased $1 \mathrm{~h}$ post-exposure, while 8-iso, 3-nitrotyrosine (3-NT) and plasma MPO increased immediately post WS-exposure. The authors concluded that these results suggest that WS exposure may cause/contribute to systemic oxidative stress.

For Barregard et al [25, 26] Danielsen et al [27] and Murgia et al [28], a conventional cast iron woodstove burned a mixture of birch and spruce logs to produce soot/organics-dominated WS. Participants were exposed for $4 \mathrm{~h}$ with two 25-min intervals of exercise on a stationary bike. In Barregard et al [25], the effect of WS exposure on cardiovascular endpoints was assessed through biomarkers of inflammation, coagulation, and oxidative stress. There was a significant increase in serum Amyloid A (SAA) and the ratio of factor VIII complex and the von Willebrand factor (VIIIc/vWf) at both $3 \mathrm{~h}$ and $20 \mathrm{~h}$ post exposure. Moreover, at $20 \mathrm{~h}$ postexposure the factor VIIIc increased in the blood and in 8 -iso-prostaglandin F2 alpha (8-iso-PGF2 $\alpha$ ) in the urine. The authors interpret these observations as evidence for increased vascular and systemic inflammation from the WS exposure that may increase the risk of cardiovascular adverse outcomes.

With regard to pulmonary effects in the same study, Barregard et al [26] reported effects of the WS exposure on markers of pulmonary inflammation and oxidative stress. Malondialdehyde (MDA) in breath condensate increased immediately post-exposure and $20 \mathrm{~h}$ post WS exposure. Exhaled nitric oxide (NO) was also shown to increase at $3 \mathrm{~h}$ post-exposure. There was also a net increase in serum club cell protein-16 (CC16) $20 \mathrm{~h}$ after WS exposure. These findings suggest that exposure to WS could cause distal pulmonary inflammation and oxidative stress.

Danielsen et al [27] assessed markers of oxidative DNA damage due to the WS exposure. A marker for DNA repair activity, hOGG1 mRNA, was significantly increased in blood due to the exposure, while the number of DNA strand breaks was decreased. In contrast, other markers of oxidative stress, including urinary excretion of 8-oxo-2'-dexyguanosine (8oxodG) and 8-oxo - 7, 8-dihydroguanine (8-oxoGua), mRNA expression levels of human MutT homolog (hNUDT1) and histone H1 (hHO1), and human 8oxoguanine glycosylase (hOGG1) activity level, were 
not affected by WS exposure. These results suggest that there was detectable upregulation of DNA damage repair mechanisms but no detectable direct genotoxic effect was found.

The final publication from this study [28] investigated the effects of WS exposure on oxidative stress through the changes of markers in EBC and urine. Murgia and colleagues reported no significant net changes in 8-iso in $\mathrm{EBC}$, however there were significant inverse correlations with other biomarkers of oxidative stress and inflammation from previous publications [26].

In Stockfelt et al $[29,30]$ a similar setup was used to Barregard at al $[25,26]$. except that WS exposure of two different phases of the combustion cycle were used, namely the start-up phase (SUP) and burn-out phase (BOP) creating soot/organics-dominated WS. For each exposure type (FA, SUP, and BOP) participants were exposed for $3 \mathrm{~h}$ at rest. Stockfelt et al [29] reported an increase in $\mathrm{CC} 16$ in the blood, $7 \mathrm{~h}$ postexposure start and $24 \mathrm{~h}$ post-exposure start in the urine from the SUP exposure. There was also a decrease in surfactant protein D (SP-D) in the blood $7 \mathrm{~h}$ post-exposure start to BOP. Finally, the levels of fractional exhaled NO (FeNO50 and FeNO270) increased significantly post exposure (see Table 2 for more details). The authors concluded that these results showed a link between WS exposure and inflammatory response in the airway.

Stockfelt et al [30] assessed markers of systemic inflammation. There was however no clear pattern of systematic inflammation post-exposure for either SUP or BOP when blood and urine data were considered. There were slight decreases in both fibrinogen and platelet counts at $24 \mathrm{~h}$ post-SUP exposure start and $7 \mathrm{~h}$ and $24 \mathrm{~h}$ post-BOP exposure start. However, a decrease in Creactive protein $(\mathrm{CRP})$ in the blood $(7 \mathrm{~h}$ post-SUP exposure start) and in 8 -iso-PGF ( $48 \mathrm{~h}$ post-SUP and $24 \mathrm{~h} / 48$ $h$ post-BOP exposure start) in urine was also an unexpected finding in this study. However, the decrease in 8iso-PGF might be part due to the increase in levels following FA exposure. In conclusion, exposure to WS, did not result in consistent increases in any systemic biomarkers.

Riddervold et al [31], Forchhammer et al [32], and Bønløkke et al [33] generated soot/ash-dominated WS that contained a combination of inorganic ash, soot and organics. This WS was generated by a conventional woodstove fuelled by beech wood logs. Participants were exposed to two different WS concentration levels (high and low) for $3 \mathrm{~h}$ at rest.

Riddervold et al [31] assessed airway effects of WS exposure in terms of changes in spirometry, FeNO, NAL and $\mathrm{EBC}$ for atopic subjects in response. The authors reported a change in conductivity and $\mathrm{pH}$ level in the $\mathrm{EBC}$ for the higher concentration of WS, which was interpreted as a mild inflammatory response. No other detectable changes were reported in spirometry, FeNO or tested NAL cytokines.

Forchhammer et al [32] investigated markers of systemic inflammation, oxidative stress and changes in microvascular function (MVF) for the same exposure study. The publication reported no significant changes in any of the endpoints after either concentration of WS exposure, including DNA damage, cell adhesion, cytokines or MVF. The authors hypothesized that the lack of effects in this study was due to the low pulmonary deposition of particles from this type of fuel and combustion conditions.

The last publication from this human controlled exposure study (Bønløkke et al [33]) measured heart rate variability (HRV) as well as cytokines, pneumoproteins and factors reflecting coagulation and adhesion. The only significant effect of WS exposure was a decrease in interleukin 6 (IL-6) at $6 \mathrm{~h}$ after exposure, similar to findings in Barregard et al [25]. However, this result seems to come from an increase in IL-6 in FA baseline. HRV and other endpoints were not affected by the exposure conditions. Despite the hypothesis presented by the authors, no significant effects were seen between the two WS exposure concentrations in this study.

Unosson et al [34] investigated the effects on the cardiovascular system after WS generated from high temperature incomplete combustion resulting in a WS exposure dominated by soot/ash. WS exposure increased the pulse wave velocity, the augmentation index and pressure as well as an increase in heart rate. There was also a noted decrease in heart rate variability postexposure. The authors concluded that these results could suggest that exposure to WS has acute effects on cardiovascular health and impact cardiovascular disease.

Muala et al [35] assessed the airway effects in the same human exposure study. Lung function and airway inflammation (FeNO) was not altered by WS exposure, but a range of the factors assessed in blood and bronchoscopy samples were significantly affected. In blood, several cell populations increased after WS exposure, including CD16 + CD56+, CD4 + HLADR+, CD8 + HLAD $\mathrm{R}$ cells. In the bronchoscopic biopsy samples there was an increase in CD3 + lymphocytes (submucosal and epithelial), CD8 + lymphocytes (epithelium), and mast cells (submucosal). In the BW, there were reductions in macrophages, neutrophils, and lymphocytes, soluble intercellular adhesion molecule (sICAM-1), MPO, matrix metallopeptidase 9 (MMP-9), and LDH. Finally, in the BAL samples there were significant increases in total lymphocyte numbers and total glutathione.

Hunter et al [36], uses the same WS exposure set-up as Unosson et al [34] to investigate effects of short 
exposure at high dose of WS on cardiovascular endpoints. Carboxyhaemoglobin $(\mathrm{COHb})$ increased significantly $3 \mathrm{~h}$ after WS exposure, while blood pressure or heart rate was not affected by the exposure. The subject's responses to bradykinin was increased after WS exposure, with an increased forearm blood flow. The authors conclude that the results suggest that acute exposures of this kind may not lead to cardiovascular events often seen in firefighters.

\section{Synopsis by endpoint}

The findings from these 12 studies (across 22 publications) may be better understood by synthesizing the results by endpoint, as summarized in Tables 2,3,4,5, where effects on lung inflammation, circulating cells and proteins, oxidative stress, and cardiovascular physiology are presented, respectively. Lung function (not summarized in table) was investigated by spirometry in 5 studies $[16,20,23,31,35]$ but no significant changes in principal spirometry values $\left(\mathrm{FEV}_{1}, \mathrm{FVC}\right.$, or $\left.\mathrm{FEV}_{1} / \mathrm{FVC}\right)$ were observed in any of the studies, even though different concentrations and properties of WS were applied.

Effects of WS exposure on airway inflammation was addressed in 9 different publications in a range of biological samples, including FeNO, EBC, and bronchoscopy (Table 2). Most endpoints were assessed in only one or two of the publications, which often differed in WS exposure conditions, making cross-study synthesis difficult. The most commonly assessed endpoints between these publications were FeNO (5 studies) and neutrophil count in BAL/BW samples (3 studies). However, none of these endpoints showed an entirely consistent signal across publications. FeNO 270, considered to be a marker of distal NO, was increased at multiple timepoints across two publications using similar WS combustion conditions [26, 29], with null results in three others. Cytokines and cell recruitment also showed inconsistent signals across studies with either significant or null findings, while EBC $\mathrm{pH}$ and bronchial wash neutrophils showed conflicting results. Neutrophil numbers were decreased at $24 \mathrm{~h}$ in Muala et al [35], but increased at $20 \mathrm{~h}$ in Ghio et al [16]. As these studies used very different WS exposures, dominated by either organics or soot/ash, differences in WS exposures and PM classes could possibly contribute to this inconsistency. Notably, the latter finding is supported by the increased sputum percentage neutrophils (\%PMNs), a close approximation of BW, in Burbank et al [17] using similar WS combustion conditions.

Markers of circulating cells and proteins were assessed in 10 publications (Table 3) in samples from blood and urine. The most common markers examined were platelets, leukocytes, IL-6, vWf, tumor necrosis factor alpha (TNF- $\alpha$ ) and CC16 in blood and CC16 in urine. Again, relatively few studies (between two and four) assessed each endpoint and there were many null findings and several inconsistencies. For several endpoints, two to four studies consistently reported null findings, including leukocytes, red blood cell (RBC), surfactant protein A (SP-A), soluble platelet selectin (sP-selectin), vWf and TNF- $\alpha$ (Table 3). Only two markers showed consistent results across the different studies: CC16 was increased in blood in two studies, while IL- 6 was decreased (although in [33] this change could be due to an increase in IL-6 at baseline during FA exposure). The latter was contrary to expectation as it is amongst the markers most consistently elevated in terms of traffic-related air pollution. Notably, the IL-6 level was also significantly decreased in NAL, but not affected in bronchial samples (Table 2).

Twelve publications assessed different markers of oxidative stress, most extensively looking at BAL/BW antioxidant markers (such as GSH, oxidized glutathione (GSSG), and total glutathione (GSx)) and a range of markers in blood, while EBC and urine oxidative stress markers were narrowly evaluated (Table 4). Each endpoint was only assessed in 1-2 studies and there were many null findings and some inconsistencies. In some cases, findings within the same study were also inconsistent [24]. One of the most studied oxidative stress signals in general, 8-isoprostane in urine, was only assessed in two publications, which showed opposite results (although as mentioned previously, the decrease seen in Stockfelt et al [30] in likely due to in part and increase following the control exposure).

Effects of WS exposure on cardiovascular physiology was investigated in seven publications, looking most commonly at heart rate variability and electrocardiogram (ECG) readings (Table 5). Most endpoints were included in two to four of the publications, but there was little consistency. Forchhammer et al [32] showed no change in microvascular function (post-ischemia peripheral artery tonometry). Similarly, in Pope et al [21] the controlled exposure did not alter vascular response (here too assessed by reactive tonometry). However, Unosson et al [34] was noteworthy in demonstrating both increased arterial stiffness and decreased heart rate variability in key metrics, which are considered adverse reactions. Ghio et al [16], however, showed a decrease in maximal heart rate but only a marginal (non-significant) change in high frequency component of HRV (Bønløkke et al. [33] showed no change in HRV). These discrepant findings regarding HRV are perhaps due to exposure time (Unosson et al [34] longer than Ghio et al) and/or inclusion of exercise (which Bønløkke et al [33] did not). Hunter et al [36] did not reproduce Ghio et al [16] maximal heart rate findings upon applying the same exposure setup for WS exposures but using a third of the exposure time and a three-fold 
higher concentration. This discrepancy could be due to the differences in WS exposure or due to the differences in participant demographics (i.e. healthy non-smokers vs. healthy firefighters). Instead in Hunter et al [36], a significant increase in the response to bradykinin was observed. Fedak et al [19] demonstrated an increase in systolic blood pressure with use of wood-burning cookstoves, in contrast to two of the wood stove studies $[34,36]$.

Overall, there was most consistency in reported effects for airways (FeNO, neutrophils, CC16), while oxidative stress, systemic inflammation and cardiovascular physiology did not show any clear patterns. However, the large differences in study design, assessed endpoints, sampling times, and WS exposure conditions (concentration, exercise intensity, PM classes) make it difficult to draw conclusions regarding (i) consistent responses within the four classes of endpoints, or (ii) the importance of physicochemical properties of WS PM.

\section{Discussion}

Perhaps the most important observation from this review is that there is great heterogeneity across study designs, in terms of stove, fuel, exposure duration, exercise during exposure, as well as selection of endpoints and timing. Accordingly, it is difficult to know whether the lack of a clear signal in these data is primarily due to heterogenous study designs or to a bonafide lack of clinically relevant pathophysiology from WS especially in the acute setting. This makes it difficult to choose a particular signal upon which to focus subsequent efforts. Such efforts are likely to remain dictated in large part by the type of physiological derangement of primary interest by the investigators, though some guidance is provided by the results summarized here.

The current data also suggest that future studies should pay particular attention to the details of the WS exposure (effective dose, clearance rate, and inherent differences a given WS' toxic potential). In addition, the applied exposure conditions should reflect the research question of the study, as both exposure levels and PM properties vary considerably between wildfires, indoor household emissions in developing countries and outdoor residential wood combustion in developed countries.

As several studies report significant effects of various wood smoke exposures on both respiratory and cardiovascular endpoints $[16,26,34]$, one should certainly not conclude that inhalation of WS is benign. Also, these studies assessed acute scenarios only, and generally focused on healthy adults who are likely resilient to such insults. Furthermore, some anatomic compartments (such as the upper airway) were minimally examined or by only very limited endpoints. Even in the lower airway, only 3 studies directly examined the lungs (by bronchoscopy) and so this represents a truly scarce set of evidence obtained precisely from the compartment that would, arguably, be most affected by WS. Similarly, regarding cardiovascular endpoints, only 2 studies investigated arterial stiffness and only 1 study investigated forearm blood flood. As a final example of minimal coverage of key endpoints, we note that only 2 studies investigated oxidative damage to DNA. There was an absence of attention to the role of co-exposures [41], systemic cellular immune responses (and related genetic predispositions) [42] or anti-microbial defence [43], important within the broader air pollution literature; these gaps should be addressed in future studies.

In design of future controlled WS exposure studies we emphasize the importance of including endpoints that have shown the most consistency, especially those that are simple to perform, such as FeNO. In addition, methods that have been of particular insight in controlled human studies of other particulate-rich pollutants, should be prioritized, such as endobronchial brushing and biopsy that were underutilized in the reviewed WS studies. With regard to cardiovascular endpoints, we consider arterial stiffness and heart rate variability as key metrics for future studies, as these are sensitive biomarkers. Moreover, harmonizing of timepoints would allow for more interstudy comparison; $24 \mathrm{~h}$ post-exposure is a preferred option given its ability to minimize diurnal variability, but the timing should be tightly aligned with known biological responses (some of which peak and fade before $24 \mathrm{~h}$ ). Finally, multicentre studies with identical (or near-identical) protocols should be pursued to increase consistency and statistical power, and also for comparison of WS dominated by different PM classes.

\section{Conclusion}

Although no clear pattern emerges from the reviewed controlled human exposure studies, one cannot conclude that WS is necessarily less toxic than trafficrelated air pollution. The latter has had a much longer period of investigation, and many more studies, allowing for a refinement of the methods that has not yet occurred in WS studies. Accordingly, conclusions regarding effects of acute WS exposure on human health are premature and more carefully conducted human studies are needed.

\section{Supplementary information}

Supplementary information accompanies this paper at https://doi.org/10. 1186/s12989-020-00375-x.

Additional file 1: Table S1. Overview of the data used as a basis for the categorization of the exposure conditions applied in the 12 human exposure studies in terms of the PM class dominating the exposure. The 
table lists references (only by name and year to avoid confusion with manuscript reference numbers), and then in bold and underlined the dominating PM class, as OC, soot or ash, or a combination of these PM classes. The categorization is based on the data reported in each study or inferred based on provided information and literature. The stove and fuel type applied in each study is listed, as well as the PM characterization data. In addition, data provided in supporting papers to draw a conclusion with regard to the PM composition is listed.

\section{Abbreviations}

BAL: Bronchoalveolar lavage; BOP: Burn-out phase; BW: Bronchial wash; CC16: Club cell protein-16; COHb: Carboxyhaemoglobin; CRP: C-reactive protein; EBC: Exhaled breath condensate; EC: Elemental carbon; ECG: Electrocardiogram; FA: Filtered air; FEV1: Forced expiratory volume; FVC: Forced vital capacity; FeNO: Fractional exhaled nitric oxide; GSH: Glutathione; GSSG: Oxidized glutathione; GSTM1: Glutathione Stransferases M1; GSx: Total glutathione; hHO1: Histone H1; hOGG1: Human 8Oxoguanine glycosylase; hNUDT1: Human MutT homolog 1; HRV: Heart rate variability; IL-1ß: Interleukin-1 beta; IL-6: Interleukin-6; IP-10: Interferon gammainduced protein 10; LDH: Lactate dehydrogenase; $\mathrm{LOOH}$ : Lipid hydroperoxides; MDA: Malondialdehyde; MMP-9: Matrix metallopeptidase-9; MPO: Myeloperoxidase; MVF/MVRI: Microvascular responsiveness index/ Microvascular function; NAL: Nasal lavage; NO: Nitric oxide; OC: Organic carbon; PAHs: Polycyclic aromatic hydrocarbons; PM: Particulate matter; PM2.5: Particulate matter of less than or equal to $2.5 \mu \mathrm{m}$ in aerodynamic diameter; pNN50: Percentage of successive NN interval greater than $50 \mathrm{~ms}$; RBC: Red blood cell; RMSSD: Square root of the mean squared differences of successive NN intervals; SAA: Serum Amyloid A; SDNN: Standard deviation of the NN interval; sICAM-1: Soluble intercellular adhesion molecule-1; SPA: Surfactant protein A; SP-D: Surfactant protein D; SP-selectin: Soluble platelet selectin; SUP: Start-up phase; SVCAM-1: Soluble vascular cell adhesion molecule-1; TEAC: Trolox equivalent antioxidant capacity; TNF-a: Tumor necrosis factor alpha; UA: Uric acid; VIIIc: Factor VIII complex; WS: Wood smoke; VWf: Von Willebrand factor; 3-NT: 3-nitrotyrosine; 8-iso-PGF2: 8-Isoprostaglandin F2alpha; 8-iso: 8-Isoprostane; 8-oxoGua: 8-Oxo-7,8dihydroguanine; 8-oxodG: 8-Oxo-2'-deoxyguanosine; \%PMN: Percentage sputum neutrophils

\section{Acknowledgements}

We thank the Legacy for Airway Health for supporting dissemination of our work.

\section{Authors' contributions}

Literature collection, distribution and establishing the first overview was done by CS. AKB Provided insight regarding wood smoke particle characterization, wrote the Supplementary Materials and developed discussion and conclusions. CC provided important insight and background and developed discussion and conclusions. All sections were commented, improved and discussed between all authors. All authors read and approved the final manuscript.

Authors' information

Not applicable.

\section{Funding}

Not applicable.

\section{Availability of data and materials}

All data reviewed and described is either included in this manuscript or available online in the relevant publications.

\section{Ethics approval and consent to participate}

$$
\text { Not applicable. }
$$

\section{Consent for publication}

Not applicable.

\section{Competing interests}

The authors declare that they have no competing interests.

\section{Author details}

'Department of Medicine, Division of Respiratory Medicine, University of British Columbia, P: 604-875-4729, 2775 Laurel Street 10th Floor, Vancouver, BC V5Z 1M9, Canada. ${ }^{2}$ Section of Air Pollution and Noise, Department of Environmental Health, Norwegian Institute of Public Health, P.O. Box 222 Skøyen, 0213 Oslo, Norway.

\section{Received: 8 April 2020 Accepted: 19 August 2020}

Published online: 02 October 2020

\section{References}

1. WHO. Household air pollution and health. Geneva: World Health Organization; 2018. https://www.who.int/en/news-room/fact-sheets/detail/ household-air-pollution-and-health. Accessed 6 Sept 2019.

2. Barry C. Increase in wood as main source of household heating most notable in the northeast. Washington (DC): U.S. Energy Information Administration; 2014. https://www.eia.gov/todayinenergy/detail.php?id= 15431. Accessed 6 Sept 2019.

3. Sigsgaard T, Forsberg B, Annesi-Maesano I, Blomberg A, Bølling A, Boman C, Bønlokke J, Brauer M, Bruce N, Heroux ME, et al. Health impacts of anthropogenic biomass burning in the developed world. Eur Respir J. 2015; 46(6):1577-88

4. National Annual Emissions Trend. Environmental Protection Agency. 2020. https://www.epa.gov/sites/production/files/2018-04/national_tier1_caps.xlsx. Accessed 14 May 2020.

5. Sun Q, Miao C, Hanel M, Borthwick AGL, Duan Q, Ji D, Li H. Global heat stress on health, wildfires, and agricultural crops under different levels of climate warming. Environ Int. 2019;128:125-36.

6. Cascio W. Wildland fire smoke and human health. Sci Total Environ. 2018; 624:586-95.

7. Bølling AK, Pagels J, Barregard L, Sallsten G, Schware PE, Boman C. Health effects of residential wood smoke particles: the importance of combustion conditions and physicochemical particles properties. Part Fibre Toxicol. 2009;6(29):1-20.

8. Liu JC, Wilson A, Mickley LJ, Dominici F, Ebisu K, Yun W, Sulprizio MP, Peng $\mathrm{RD}$, Yue $X$, Son JY, et al. Wildfire-specific fine particulate matter and risk of hospital admissions in urban and rural counties. Epidemiology. 2017;28(1): $77-85$.

9. Löndahl J, Pagels J, Boman C, Swietlicki E, Massling A, Rissler J, Blomberg A, Bohgard M, Sandström T. Deposition of biomass combustion aerosol particles in the human respiratory tract. Inhal Toxicol. 2008;20(10):923-33.

10. Löndahl J, Massling A, Swietlicki E, Bräuner EV, Ketzel M, Pagels J, Loft S. Experimentally determined human respiratory tract deposition of airborne particles at a busy street. Environ Sci Technol. 2009;43(13):4659-64.

11. Kristensson A, Rissler J, Londahl J, et al. Size-resolved respiratory tract deposition of sub-micrometer aerosol particles in a residential area with wintertime wood combustion. Aerosol Air Qual Res. 2013;13:24-35.

12. Naeher LP, Brauer M, Lipsett M, Zelikoff JT, Simpson CD, Koenig JQ, Smith KR. Woodsmoke health effects: a review. Inhal Toxicol. 2007;19(1):67-106.

13. Rokoff LB, Koutrakis P, Garshick E, Karagas MR, Oken E, Gold DR, Fleisch AF. Wood stove pollution in the developed world: a case to raise awareness among pediatricians. Curr Prob Pediarr Ad. 2017;47(6):123-41.

14. Groot E, Caturay A, Khan Y, Copes R. A systematic review of the health impacts of occupational exposure to wildland fires. Int J Occup Environ Health. 2019;32(2):121-40.

15. Scott A, Reilly C. Wood and biomass smoke: addressing human health risks and exposures. Chem Res Toxicol. 2019;32(2):219-21.

16. Ghio AJ, Soukup JM, Case M, Dailey LA, Richards J, Berntsen J, Devlin RB, Stone S, Rappold A. Exposure to WS particles produces inflammation in healthy volunteers. Occup Environ Med. 2012;69(3):170-5.

17. Burbank AJ, Vadlamudi A, Mills KH, Alt EM, Wells $\mathrm{H}$, Zhou H, Alexis $\mathrm{N}$, Hernandez ML, Peden DB. The glutathione-S-transferase mu-1 null genotype increases WS-induced airway inflammation. J Allergy Clin Immunlo. 2019;143(6):2299-302.

18. Rebuli ME, Speen AM, Martin EM, Addo KA, Pawlak EA, Glista-Baker E, Robinette C, Zhou H, Noah TL, Jaspers I. WS exposure alters human inflammatory responses to viral infection in a sex-specific manner: a randomized, placebo-controlled study. Am J Respir Crit Care Med. 2019; 199(8):996-1007.

19. Fedak KM, Good N, Walker ES, Balmes J, Brook RD, Clark ML, Cole-Hunter T, Devlin R, L'Orange C, Luckasen $G$, et al. Acute effects on blood pressure 
following controlled exposure to cookstove air pollution in the STOVES study. J Am Heart Assoc. 2019;8:012246.

20. Sehlstedt M, Dove R, Boman C, Pagels J, Swietlicki E, Londahl J, Westerholm $\mathrm{R}$, Bosson J, Barath S, Behndig AF, et al. Antioxidant airway responses following experimental exposure to WS in man. Part Fibre Toxicol. 2010;7:111.

21. Pope AC, Hansen JC, Kuprov R, Sanders MD, Anderson MN, Eatough DJ. Vascular function and short-term exposure to fine particulate air pollution. J Air Waste Manage Assoc. 2011;61:858-63.

22. Ferguson MD, Semmens EO, Dumke C, Quindry JC, Ward TJ. Measured pulmonary and systemic markers of inflammation and oxidative stress following wildland firefighter simulations. J Occup Environ Med. 2016;58(4): 407-13.

23. Ferguson MD, Semmens EO, Weiler E, Domitrovich J, French M, Migliaccio C, Palmer C, Dumke C, Ward T. Lung function measures following simulated wildland firefighter exposures. J Occup Environ Hyg. 2017;14(9):739-48.

24. Peters B, Ballmann C, Quindry T, Zehner EG, McCroskey J, Ferguson M, Ward T, Dumke C, Quindry JC. Experimental woodsmoke exposure during exercise and blood oxidative stress. J Occup Environ Med. 2018;60(12):107381.

25. Barregard L, Sallsten G, Gustafson P, Andersson L, Johansson L. Experimental exposure to wood-smoke particles in healthy humans: effects on markers of inflammation, coagulation, and lipid peroxidation. Inhal Toxicol. 2006;18(11): 845-53.

26. Barregard L, Sallsten G, Andersson L, Almstrand AC, Gustafson P, Andersson $M$, Olin AC. Experimental exposure to wood smoke: effects on airway inflammation and oxidative stress. Occup Environ Med. 2008;65(5):319-24.

27. Danielsen PH, Brauner EV, Barregard L, Sallsten G, Wallin M, Olinski R, Rozalski R, Moller P, Loft S. Oxidatively damaged DNA and its repair after experimental exposure to WS in healthy humans. Mutat Res. 2008;642(1-2): $37-42$.

28. Murgia N, Barregard L, Sallsten G, Almstrand AC, Montuschi P, Ciabattoni G, Olin AC. 8-isoprostande in exhaled breath condensate after experimental exposure to wood smoke in humans. J Biol Reg Homeos Ag. 2016;30(1): 263-70.

29. Stockfelt L, Sallsten G, Olin AC, Almerud P, Samuelsson L, Johannesson S, Molnar P, Strandberg B, Almstrand AC, Bergemalm-Rynell K, Barregard L. Effects on airways of short-term exposure to two kinds of WS in a chamber study of healthy humans. Inhal Toxicol. 2012;24(1):47-54.

30. Stockfelt L, Sallsten G, Almerud P, Basu S, Barregard L. Short-term chamber exposure to low doses of two kinds of WS does not induce systemic inflammation, coagulation or oxidative stress in healthy humans. Inhal Toxicol. 2013;25(8):417-25.

31. Riddervold IS, Bonlokke JH, Olin AC, Gronborg TK, Schlunssen V, Skogstrand K, Hougaard D, Massling A, Sigsgaard T. Effects of WS particles from woodburning stoves on the respiratory health of atopic humans. Part Fibre Toxicol. 2012:9:12.

32. Forchhammer L, Moller P, Riddervold IS, Bonlokke J, Massling A, Sigsgaard T, Loft S. Controlled human wood smoke exposure: oxidative stress, inflammation and microvascular function. Part Fibre Toxicol. 2012;9:1-11.

33. Bønløkke JH, Riddervold IS, Gronborg TK, Skogstrand K, Hougaard DM, Barregard L, Sigsgaard T. Systemic effects of WS in a short-term experimental exposure study of atopic volunteers. J Occup Environ Med. 2014;56(2):177-83.

34. Unosson J, Blomberg A, Sandstrom T, Muala A, Boman C, Nystrom R Westerholm R, Mills NL, Newby DE, Langrish JP, Bosson JA. Exposure to WS increases arterial stiffness and decreases heart rate variability in humans. Part Fibre Toxicol. 2013;10(1):1-8.

35. Muala A, Rankin G, Sehlstedt M, Unosson J, Bosson JA, Behndig A, Pourazar J, Nystrom R, Pettersson EE, Bergvall C, et al. Acute exposure to WS from incomplete combustion - indications of cytotoxicity. Part Fibre Toxicol. 2015; 12(1):1-14.

36. Hunter AL, Unosson J, Bosson JA, Langrish JP, Pourazar J, Raftis JB, Miller MR, Lucking AJ, Boman C, Nyström R, et al. Effect of wood smoke exposure on vascular function and thrombus formation in healthy fire fighters. Part Fibre Toxicol. 2014;11(1):1-13.

37. Oravisjarvi K, Pietikainen M, Ruuskanen J, Rautio A, Voutilainen A, Keiski RL. Effects of physical activity on the deposition of traffic-related particles into the human lungs in silico. Sci Total Environ. 2011;409(21):4511-8.

38. Riddervold IS, Bønløkke JH, Molhave L, Massling A, Jensen B, Grønborg TK, Bossi R, Forchhammer L, Kjaergaard SK, Sigsgaard T, et al. WS in a controlled exposure experiment with human volunteers. Inhal Toxicol. 2011;23(5):27788.

39. Glantzounis GK, Tsimoyiannis EC, Kappas AM, Galaris DA. Uric acid and oxidative stress. Curr Pharm Des. 2005:11(32):4145-51.

40. Ghiselli A, Serafini M, Natella F, Scaccini C. Total antioxidant capacity as a tool to assess redox status: critical view and experimental data. Free Radic Biol Med. 2000;29(11):1106-14.

41. Blais CM, Davis BE, Graham BL, Cockcroft DW. Respiratory duty cycles in individuals with and without airway hyperresponsiveness. Chest. 2020; 157(2):356-62.

42. Wooding DJ, Ryu MH, Hüls A, Lee AD, Lin DTS, Rider CF, Yuen AC, Carlsten C. Particle depletion does not remediate acute effects of traffic-related air pollution and allergen. A randomized, double-bling crossover study. Am J Respir Crit Care. 2019;200(5):565-74.

43. Piyadasa H, Hemshekhar M, Carlsten C, Mookherjee N. Inhaled diesel exhaust decreases the antimicrobial peptides a-defensin and S100A7 in human bronchial secretions. Am J Respir Crit Care. 2018;197(10):1358-61.

\section{Publisher's Note}

Springer Nature remains neutral with regard to jurisdictional claims in published maps and institutional affiliations.

\section{Ready to submit your research? Choose BMC and benefit from:}

- fast, convenient online submission

- thorough peer review by experienced researchers in your field

- rapid publication on acceptance

- support for research data, including large and complex data types

- gold Open Access which fosters wider collaboration and increased citations

- maximum visibility for your research: over $100 \mathrm{M}$ website views per year

At BMC, research is always in progress.

Learn more biomedcentral.com/submissions 